\title{
DAMPAK BIMTEK DARING PEMBATIK LEVEL DUA TERHADAP KEMAMPUAN TIK GURU PROVINSI JAWA TIMUR
}

\section{The Impact of Online Level Two PembaTIK on Teachers' ICT Ability in East Java Province}

\author{
Raden Roro Martiningsih \\ SMP Muhammadiyah 1 Surabaya \\ Jalan Simolawang Baru 25-27 Surabaya, Jawa Timur, Indonesia \\ radenroromartiningsih@gmail.com
}

\begin{abstract}
Diterima: ABSTRACT: Duta Rumah Belajar merupakan perpanjangan
17 Agustus 2018, tangan Pustekkom, yang kini bernama Pusdatin, dalam

Direvisi:

15 Januari 2019, menyosialisasikan Portal Rumah Belajar kepada guru sehingga guru perlu menjaring Duta Rumah Belajar Tahun 2018 melalui

Disetujui:

17 Mei 2021

Bimbingan Teknis (Bimtek) Pembelajaran Berbasis TIK (PembaTIK) yang dilaksanakan tahun 2018 secara daring. Tujuan penelitian ini adalah untuk mengetahui dampak Bimtek PembaTIK Level 2 yang diikuti oleh peserta dari Jawa Timur. Bagaimana upaya peserta Bimtek menyelesaikan tugasnya? Apa manfaat Bimtek bagi peserta? Apa hambatan yang dialami peserta selama Bimtek berlangsung? Bagaimana solusi pemecahan masalahnya? Penelitian ini adalah penelitian deskriptif dengan online survey. Responden dalam penelitian ini adalah 240 pendidik yang menjadi peserta Bimtek Daring PembaTIK Level 2. Data diperoleh dari online survey, observasi, dan wawancara 76 guru dinyatakan lulus. Dampak Bimtek Daring bagi peserta adalah memudahkan guru untuk mengikuti pelatihan. Mereka dapat mengikuti pelatihan dari mana saja, kapan saja, dan tentunya dengan biaya yang lebih murah. Hambatan yang dialami peserta adalah rasa tidak percaya diri. Mereka khawatir bersaing dengan guru lain yang lebih hebat. Selain itu, kurangnya sarana dan prasarana yang mendukung aktivitas peserta Bimtek Daring PembaTIK Level 2 juga merupakan pemicu peserta menjadi tidak aktif. Hambatan tersebut diatasi dengan komunikasi yang baik antara peserta dan fasilitator.
\end{abstract}

Kata Kunci: Duta Rumah Belajar, Bimtek Daring, Pembatik Level Dua.

ABSTRACT: Ambassador of Rumah Belajar is an extension of Pustekkom, which is now named Pusdatin, in socializing the Rumah Belajar Portal to teachers, so it is necessary to capture the Ambassador of Rumah Belajar in 2018 through Online Technical Training. The objective of this study is to describe the impact of Level 2 of PembaTIK Online Technical Training in 2018 in East Java: How the participants do their assignments; What benefit they can get from the Online Technical Training; What obstacles they face during the training; and How they solve the obstacles. This study is a descriptive study with online survey. The respondents of this study are 240 teachers who participate 
Raden Roro Martiningsih: Dampak Bimtek Daring Pembatik Level Dua Terhadap Kemampuan Tik Guru Provinsi Jawa Timur

\begin{abstract}
in PembaTIK Online Technical Training of Level Two. The data is acquired from online survey, observation, and interview. Seventysix teachers are declared to pass the training. The impact of PembaTIK Online Technical Training is that the participants find it easier for them to attend a training. They do not have to come to Pusdatin. They can attend a training from anywhere, at any time, and with lower budget. The obstacles that the participants face is that they are unconfident to compete with other teachers. Besides, the lack of infrastructure that can support the participants' activities in PEMBATIK Online Technical Training of Level Two is also an obstacle that contribute to the participants' inactivity. The obstacle is solved by performing good communication between the participants and the facilitators.
\end{abstract}

Keywords: Ambassador of Rumah Belajar, Online Technical Training, Pembatik Level Two.

\title{
PENDAHULUAN
}

Duta Rumah Belajar merupakan perpanjangan tangan Pustekkom, yang kini bernama Pusdatin, dalam menyosialisasikan Portal Rumah Belajar bagi guru sehingga perlu menjaring Duta Rumah Belajar Tahun 2018 melalui Bimtek PembaTIK daring. Di era revolusi industri 4.0, penggunaan teknologi merupakan keniscayaan untuk mendukung kemajuan pendidikan masa depan. Demikan halnya Bimtek PembaTIK yang dilaksanakan secara daring yang tidak terbatasi oleh jarak dan waktu tentu saja sangat bergantung dengan kemajuan teknologi saat ini (Hariani, 2020:46).

Pola Bimtek PembaTIK level dua secara online perlu persiapan yang matang dari sisi materi. Pendidikan jarak jauh adalah pendidikan yang peserta didiknya terpisah dari pendidik. Dalam hal ini pembelajarannya menggunakan berbagai sumber belajar yang diakses melalui teknologi komunikasi, informasi, dan media lain.

Teknologi informasi saat ini berkembang dengan sangat pesat sehingga mengubah peserta Bimtek PembaTIK level dua dalam mencari dan mendapatkan informasi, yang tidak lagi terbatas pada informasi audio visual dan elektronik saja, tetapi juga sumbersumber informasi lainnya yang salah satu di antaranya melalui jaringan Internet (Elyas, 2018:1).
Bimtek PembaTIK Daring ini menerapkan proses komunikasi dan informasi dari tutor kepada peserta yang berisi informasiinformasi dengan melibatkan unsur pendidik dengan memanfaatkan berbagai media sebagai sarana penyajian ide, gagasan, dan materi bimtek kepada peserta. Beberapa bagian unsur ini mendapatkan sentuhan media teknologi informasi sehingga mencetuskan lahirnya ide tentang online learning.

Pusat Data dan Teknologi Informasi (Pusdatin) Kemendikbudristek, yang sebelumnya bernama Pustekkom Kemendikbud, sejak tahun 2011 telah mengembangkan portal pembelajaran Rumah Belajar yang berisikan konten-konten pembelajaran dan aplikasi e-pembelajaran untuk siswa, guru, dan masyarakat umum (Marti, 2018:1). Portal Rumah Belajar telah dimanfaatkan secara luas di seluruh Indonesia, baik oleh guru, siswa, maupun komunitas. Portal Rumah Belajar dapat diakses pada url belajar.kemdikbud.go.id memiliki jargon belajar di mana saja, kapan saja, dan dengan siapa saja. Rumah Belajar memiliki delapan fitur utama dan tiga fitur tambahan serta berbagai tautan yang mampu membawa siswa untuk belajar sesuai kebutuhan belajar abad ke-21. Kehidupan di abad ke-21 memerlukan berbagai keterampilan yang harus dikuasai siswa 
Raden Roro Martiningsih: Dampak Bimtek Daring Pembatik Level Dua Terhadap Kemampuan Tik Guru

Provinsi Jawa Timur

sehingga diharapkan pendidikan dapat mempersiapkan siswa untuk mampu menguasai berbagai keterampilan. Siswa harus menguasai empat pilar kehidupan yang mencakup learning to know, learning to do, learning to be, dan learning to live together (Astuti, 2016:41).

Rumah Belajar dapat dimanfaatkan sebagai bahan pembelajaran oleh peserta didik secara menyenangkan, tidak hanya mendengarkan ceramah guru di kelas tapi juga dapat belajar mandiri dengan materimateri pelajaran yang sama dengan yang diberikan oleh guru di sekolah. Pembelajaran yang akan digunakan dalam penelitian ini adalah pembelajaran melalui Portal Rumah Belajar. Melalui Rumah Belajar, ketuntasan hasil belajar peserta didik pada materi yang sulit diharapkan dapat tercapai (Mulyadi, 2015: 3).

Rumah Belajar adalah sebuah portal pendidikan yang sesuai dengan perkembangan dunia global saat ini yaitu berkembangnya teknologi informasi yang sangat cepat dan telah menyentuh ke berbagai sisi kehidupan. Materi yang disampaikan di Rumah Belajar disajikan dalam bentuk elektronik dan ditempatkan dalam website (e-learning) sehingga mudah diakses melalui url belajar.kemdikbud.go.id. Pembelajaran berbasis web (web based learning) adalah suatu sistem belajar yang berbasis teknologi informasi dengan menggunakan website sebagai media dalam proses pembelajaran (Kurniati, 2014: 1).

Sebagian guru mungkin akan mengatakan bahwa mengajar dengan menggunakan buku teks saja, para peserta didiknya sudah memperlihatkan prestasi belajar yang memadai atau bahkan membanggakan. Kemungkinan sebagian guru lainnya akan mengatakan bahwa mencari sumber-sumber lainnya di luar buku teks yang sudah ditetapkan tentulah menyita waktu di samping membutuhkan biaya. Sebagian guru lainnya kemungkinan akan mengatakan bahwa untuk apa repot-repot memikirkan pemanfaatan berbagai sumber belajar dalam kegiatan belajar-mengajar jika tidak ada konsekuensinya yang dapat dirasakan.
Penggunaan Portal Rumah Belajar sebagai media dianggap sesuai karena menurut Mutmainah (2017:15), peran guru dalam proses pembelajaran yang mengintegrasikan Teknologi Informasi dan Komunikasi (TIK) diharapkan sebagai fasilitator, kolaborator, mentor, pelatih, pengarah, dan teman belajar, serta dapat memberikan pilihan dan tanggung jawab yang besar kepada peserta didik untuk mengalami peristiwa belajar.

Potensi peluang dan manfaat terkait dengan penggunaan portal Rumah Belajar dalam pendidikan banyak ragamnya. Kapasitas portal Rumah Belajar untuk mencapai peserta didik di mana saja dan kapan saja membawa perubahan dalam paradigma pendidikan tradisional dengan menghilangkan premis bahwa waktu belajar sama dengan waktu di dalam kelas. Dengan aktif serta akses di mana saja dan kapan saja, TIK memberikan materi yang peserta didik butuhkan kapan saja dan di mana saja mereka menginginkannya. Portal Rumah Belajar memungkinkan mereka untuk berinteraksi tanpa batasan ruang dan waktu dengan para guru dan kelompoknya. Guru dapat mengambil keuntungan dari sistem interaktif yang membantu peserta didik memahami kebutuhan pembelajar dan kinerja yang lebih akurat, serta membuat penilaian yang lebih efektif (Fitriyadi, 2013: 272).

Duta Rumah Belajar merupakan perpanjangan tangan dari Pusat Data dan Teknologi Informasi Kemendikbudristek, dalam melakukan sosialisasi pemanfaatan Portal Rumah Belajar sebagai media pembelajaran berbasis teknologi informasi dan komunikasi di masing-masing provinsinya. Keuntungan menjadi Duta Rumah Belajar adalah: (1) berkesempatan mengikuti bimbingan teknis pengembangan bahan ajar berbasis TIK baik di pusat maupun daerah; (2) berkesempatan dilibatkan pada kegiatan Pusdatin baik di pusat maupun daerah; (3) bertemu dan bertukar wawasan dengan guru-guru dari seluruh provinsi di Indonesia; dan (4) mendapatkan segudang pengalaman dalam memajukan pendidikan di Indonesia melalui TIK (Pustekkom, 2018:1). 
Raden Roro Martiningsih: Dampak Bimtek Daring Pembatik Level Dua Terhadap Kemampuan Tik Guru Provinsi Jawa Timur

Salah satu upaya penting yang dilakukan untuk meningkatkan kompetensi guru adalah melalui kegiatan pelatihan. Pemerintah melalui Kemendikbud telah melakukan penyempurnaan sistem pembinaan dan peningkatan kompetensi guru melalui pelatihan berbasis kompetensi (Julifan, 2015: 1). Seorang guru harus memiliki kesadaran dan memotivasi diri serta mendedikasikan dirinya untuk selalu meng-upgrade kompetensi dan profesionalitasnya serta mampu beradaptasi dengan perkembangan ilmu pengetahuan dan teknologi (Richardo, 2016: 779).

Tahapan pelaksanaan pemilihan Duta Rumah Belajar tahun 2018 terintegrasi dalam program PembaTIK melalui serangkaian proses yang menggambarkan peningkatan kompetensi TIK guru meliputi: (1) Level satu (Literasi TIK) dilaksanakan pada bulan Maret sampai dengan April 2018. Registrasi peserta dilakukan melalui aplikasi Simpatik (simpatik.belajar.kemdikbud.go.id) dan bergabung pada kelas bimtek online PembaTIK level satu provinsinya masingmasing. Peserta bimtek mengunduh modul dan melakukan pembelajaran mandiri. Ujian akhir bimtek online level satu dilaksanakan setelah selesainya pembelajaran. Bila lulus, peserta akan mendapatkan sertifikat. Bimtek daring adalah sistem manajemen diklat yang dikelola secara elektronik, yakni menggunakan pengelolaan berbasis komputer (Landistyas, 2012: 29); (2) Level dua (Implementasi TIK) diikuti oleh peserta yanglulus level satu. Peserta mengikuti bimtek online level dua menggunakan aplikasi Simpatik. Pada level 2 peserta mendapat tugas membuat bahan ajar sederhana dan mengikuti ujian akhir. Bila lulus, peserta akan mendapatkan sertifikat level dua; (3) Level tiga (Kreasi TIK). Pada tahap ini, dari kelompok peserta yang lulus level dua, dipilih sebanyak 30 peserta terbaik yang akan melanjutkan ke Level Tiga. Peserta mengikuti bimtek level tiga. Bimtek PembaTIK level tiga diselenggarakan secara tatap muka di tingkat provinsi. Peserta menyempurnakan bahan ajar yang telah dibuat. Bila lulus, peserta akan mendapatkan sertifikat level tiga; (4) Level empat (berbagi). Peserta terbaik level tiga mendapat kesempatan mengikuti bimtek PembaTIK level empat yang dikemas dalam kegiatan Lokakarya. Peserta melakukan presentasi di tingkat nasional. Dapat disimpulkan bahwa bimtek PembaTIK pada setiap level diakhiri dengan ujian sehingga bersifat kompetisi. Peserta yang lulus pada level 4 mendapat kesempatan mengikuti seleksi calon Duta Rumah Belajar Nasional 2018. Peserta dikukuhkan sebagai Duta Rumah Belajar tingkat provinsi dan mendapatkan sertifikat level empat. Peserta terbaik level empat dikukuhkan sebagai Duta Rumah Belajar Nasional.

Di Wilayah Jawa Timur terjaring 458 peserta yang tersebar merata dari 38 kabupaten/kota di Jawa Timur. Peserta mengunduh modul dari aplikasi dan mempelajari modul tersebut kurang lebih selama dua pekan. Selanjutnya, peserta mengikuti ujian level satu. Pada ujian level satu, 240 guru dinyatakan lulus dan mendapatkan sertifikat. Peserta yang lulus level satu selanjutnya mengikuti level dua. Bimtek daring merupakan wujud literasi digital. Literasi digital merupakan kemampuan menggunakan teknologi dan informasi dari piranti digital secara efektif dan efisien dalam berbagai konteks (Kurnianingsih, 2017:62).

Pada level dua dilakukan dengan cara registrasi di aplikasi Simpatik, peserta dari Jawa Timur login di kelas $D$ bersama dengan peserta Daerah Istimewa Yogyakarta. Peserta membuat bahan ajar sederhana dengan menggunakan aplikasi video sederhana berdasarkan RPP pada bidang yang diampu. Metode-metode yang digunakan dalam bimtek, pelaksanaannya disesuaikan dengan situasi dan kondisi setempat atau disesuaikan dengan kebutuhan setiap provinsi. Metode yang dilaksanakan adalah belajar secara daring kemudian mengikuti ujian online, diskusi, dan pelatihan menggunakan praktik pemanfaatan Rumah Bejar, membuat RPP, dan membuat video (Kornelius, 2014: 1815).

Keberhasilan Bimtek Daring PembaTIK Level 2 sangat tergantung dari beberapa komponen, baik peserta pelatihan, fasilitator, materi pelatihan, maupun teknologi informasi. 
Komponen-komponen tersebut harus terintegrasi sehingga benar-benar dapat menghasilkan peserta pelatihan yang berkualitas untuk mengikuti Bimtek Daring PembaTIK Level 3.

Berdasarkan apa yang telah disampaikan di atas, peneliti ingin mendeskripsikan bagaimana upaya peserta Bimtek PembaTIK level dua menyelesaikan tugasnya, apa manfaat bimtek bagi peserta, mengetahui hambatan yang dialami peserta selama bimtek level dua berlangsung, dan bagaimana solusi pemecahan masalahnya. Tulisan ini dianggap perlu untuk memberikan masukan dalam penyempurnaan Bimtek PembaTIK di masa yang akan datang. Bimtek Daring PembaTIK Level 2 merupakan satu langkah maju yang dikembangkan Pustekkom dalam menggunakan teknologi jaringan dan teknologi informasi untuk pengembangan sistem pelatihan secara daring.

\section{METODA}

Penelitian ini adalah penelitian deskriptif dengan metode survei. Salah satu instrumen untuk mengumpulkan data dan bahan-bahan adalah metode survei (Adiyanta, 2019: 697). Dalam penelitian ini pengumpulan data menggunakan online survey.

Penelitian deskriptif dipilih karena peneliti ingin mendeskripsikan bagaimana aktivitas peserta Bimtek PembaTIK level dua dalam membuat RPP, keberhasilan peserta membuat video, ujian akhir memanfaatkan Rumah Belajar dalam pembelajaran, serta bagaimana aktivitas diskusi di dalam kelas secara virtual (Linarwati, 2016: 1).

Responden dalam penelitian ini adalah 240 pendidik yang menjadi peserta Bimtek PembaTIK level dua. Peserta diarahkan untuk membuka akun telegram untuk memudahkan pengguna saling berkirim pesan teks, audio, video, gambar, dan sticker dengan aman (Nova, 2018:3).

Instrumen yang digunakan adalah kuisioner online survey, lembar observasi, dan wawancara. Online survey menggunakan aplikasi PembaTIK yang diakses melalui simpatik.belajar.kemdikbud.go.id. Lembar observasi digunakan untuk mengamati aktivitas peserta Bimtek PembaTIK level dua, keberhasilan peserta membuat RPP, membuat video, memanfaatkan Rumah Belajar dalam pembelajaran, serta melaksanakan aktivitas diskusi di dalam kelas secara virtual. Instrumen yang lain adalah daftar wawancara, untuk menyatakan bagaimana peserta dapat menyelesaikan tugasnya, apa manfaat bimtek bagi peserta, mengetahui hambatan yang dialami peserta selama Bimtek PembaTIK level dua berlangsung, dan bagaimana solusi pemecahan masalahnya. Teknik analisis data berupa analisis deskriptif, yaitu dengan cara mendeskripsikan data yang diperoleh dan kemudian memaknai data tersebut.

\section{HASIL DAN PEMBAHASAN}

Online survey, observasi, dan wawancara berkaitan dengan upaya peserta Bimtek PembaTIK level dua menyelesaikan tugasnya, manfaat Bimtek PembaTIK bagi peserta, mengetahui hambatan yang dialami peserta selama Bimtek PembaTIK level dua berlangsung, dan bagaimana solusi pemecahan masalahnya. Sejauh mana upaya peserta dalam mengikuti Bimtek Pembelajaran Berbasis TIK ini bisa diamati pada Tabel 1 berikut.

Tabel 1. Aktivitas Peserta

\begin{tabular}{lll}
\hline Aktivitas & Jumlah & Persentase \\
\hline Aktif & 121 & 50,42 \\
\hline Tidak Aktif & 119 & 49,58 \\
\hline Total & $\mathbf{2 4 0}$ & $\mathbf{1 0 0 , 0 0}$ \\
\hline
\end{tabular}

Dari Tabel 1 dapat diketahui bahwa dari 240 peserta yang lulus level dua, yang aktif mengikuti Bimtek PembaTIK Daring level dua dan mengerjakan tugas-tugasnya ada 121 guru $(50,42 \%)$ dan yang tidak aktif dan tidak mengerjakan tugas-tugasnya ada 119 guru $(49,58 \%)$. Lebih jelas lagi, tampak dalam Diagram 1 berikut. 
Raden Roro Martiningsih: Dampak Bimtek Daring Pembatik Level Dua Terhadap Kemampuan Tik Guru Provinsi Jawa Timur

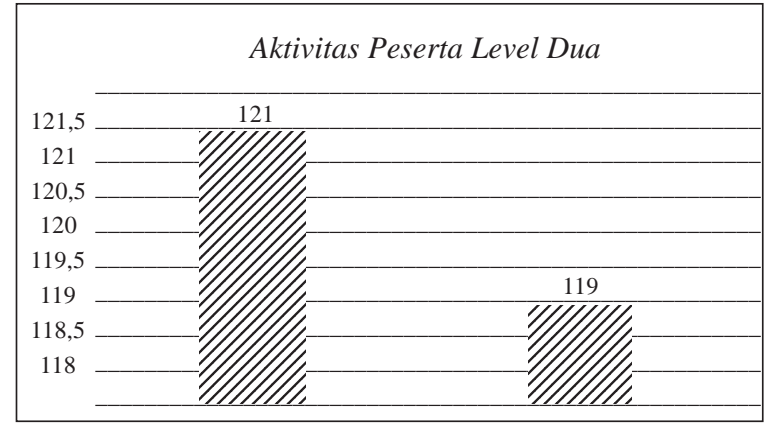

Diagram 1. Aktivitas Peserta Level Dua Pembatik Rumah Belajar

Dari peserta yang aktif, dapat diketahui bahwa 41 orang $(33,88 \%)$ merupakan guru sekolah dasar atau madrasah ibtidaiyah, 28 orang $(23,14 \%)$ merupakan guru sekolah menengah pertama atau madrasah tsanawiyah, 26 orang $(21,49 \%)$ merupakan guru sekolah menengah atas atau madrasah aliyah, dan 26 orang $(21,49 \%)$ merupakan guru sekolah menengah kejuruan, sebagaimana Tabel 2 dan Diagram 2 berikut ini.

Tabel 2. Jenjang Sekolah Tempat Peserta Level Dua Mengajar

\begin{tabular}{lcc}
\hline Jenjang & Jumlah & Persentase \\
\hline SD/MI & 41 & 33,88 \\
\hline SMP/MTS & 28 & 23,14 \\
\hline SMA/MA & 26 & 21,49 \\
\hline SMK & 26 & 21,49 \\
\hline Total & $\mathbf{1 2 1}$ & $\mathbf{1 0 0 , 0 0}$ \\
\hline
\end{tabular}

Peserta yang aktif di Level Dua

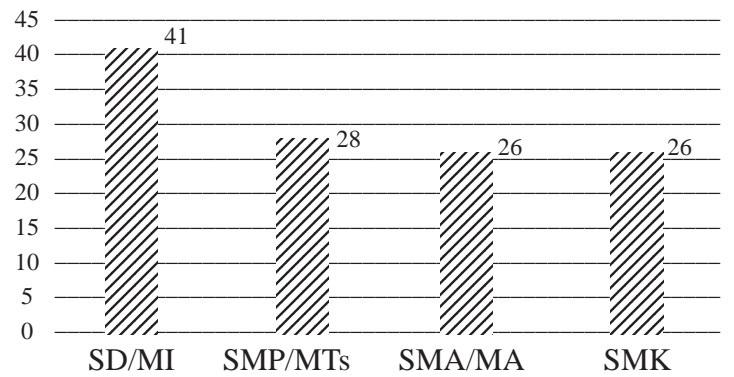

Diagram 2. Tempat Mengajar Peserta yang Aktif di Level Dua
Selanjutnya untuk melihat aktivitas 121 peserta aktif dan menuntaskan proses pembelajaran disajikan pada Tabel 3 berikut ini.

Tabel 3. Hasil Aktivitas Tugas oleh Peserta

\begin{tabular}{|c|c|c|c|c|c|}
\hline No & Tugas & Diskusi & Ujian & Keterangan & Nilai \\
\hline 1 & 40 & 14 & 23,7 & Lulus & 78,5 \\
\hline 2 & 40 & 14 & 25,5 & Lulus & 78,6 \\
\hline 3 & 0 & 0 & 11,7 & Tidak Lulus & 11,7 \\
\hline 4 & 38,75 & 0 & 0 & Tidak Lulus & 25,8 \\
\hline 5 & 45 & 14 & 18,3 & Lulus & 76,4 \\
\hline 6 & 42,5 & 14 & 23,7 & Lulus & 81,8 \\
\hline 7 & 42,5 & 14 & 20,1 & Lulus & 75,7 \\
\hline 8 & 42,5 & 14 & 22,8 & Lulus & 81 \\
\hline 9 & 40 & 14 & 24,6 & Lulus & 79,4 \\
\hline 10 & 37,5 & 14 & 17,4 & Tidak Lulus & 71,4 \\
\hline 11 & 45 & 14 & 22,8 & Lulus & 81 \\
\hline 12 & 42,5 & 14 & 23,7 & Lulus & 81,6 \\
\hline 13 & 42,5 & 14 & 23,7 & Lulus & 81 \\
\hline 14 & 45 & 0 & 25,5 & Tidak Lulus & 69,6 \\
\hline 15 & 42,5 & 14 & 0 & Tidak Lulus & 56,5 \\
\hline 16 & 40 & 14 & 23,7 & Lulus & 78,5 \\
\hline 17 & 42,5 & 14 & 15,6 & Lulus & 72,1 \\
\hline 18 & 40 & 14 & 23,7 & Lulus & 78,5 \\
\hline 19 & 40 & 14 & 15,6 & Tidak Lulus & 70,4 \\
\hline 20 & 42,5 & 14 & 21,9 & Lulus & 76,7 \\
\hline 21 & 40 & 14 & 19,2 & Lulus & 74,8 \\
\hline 22 & 42,5 & 14 & 21 & Lulus & 78,3 \\
\hline 23 & 42,5 & 14 & 19,2 & Lulus & 78,2 \\
\hline 24 & 0 & 0 & 20,1 & Tidak Lulus & 20,1 \\
\hline 25 & 45 & 14 & 26,4 & Lulus & 85,4 \\
\hline 26 & 42,5 & 14 & 15,6 & Lulus & 73 \\
\hline 27 & 40 & 14 & 20,1 & Lulus & 60,7 \\
\hline 28 & 40 & 14 & 21 & Lulus & 76,6 \\
\hline 29 & 45 & 14 & 20,1 & Lulus & 90 \\
\hline 30 & 42,5 & 14 & 20,1 & Lulus & 77,4 \\
\hline 31 & 42,5 & 14 & 21 & Lulus & 80 \\
\hline 32 & 42,5 & 14 & 23,7 & Lulus & 81,8 \\
\hline 33 & 41,25 & 14 & 22,8 & Tidak Lulus & 64,3 \\
\hline 34 & 45 & 14 & 20,1 & Tidak Lulus & 64,1 \\
\hline 35 & 40 & 14 & 21,9 & Lulus & 78,4 \\
\hline 36 & 40 & 14 & 21 & Lulus & 74,2 \\
\hline 37 & 42,5 & 14 & 23,7 & Lulus & 81 \\
\hline 38 & 42,5 & 14 & 21 & Tidak Lulus & 62,5 \\
\hline
\end{tabular}


Raden Roro Martiningsih: Dampak Bimtek Daring Pembatik Level Dua Terhadap Kemampuan Tik Guru Provinsi Jawa Timur

\begin{tabular}{|c|c|c|c|c|c|c|c|c|c|c|c|}
\hline No & Tugas & Diskusi & Ujian & Keterangan & Nilai & No & Tugas & Diskusi & Ujian & Keterangan & Nilai \\
\hline 39 & 42,5 & 14 & 16,5 & Lulus & 74,6 & 81 & 20 & 14 & 21,9 & Tidak Lulus & 64,2 \\
\hline 40 & 42,5 & 14 & 20,1 & Lulus & 77,4 & 82 & 42,5 & 14 & 20,1 & Lulus & 77,4 \\
\hline 41 & 37,5 & 14 & 15,6 & Tidak Lulus & 53,7 & 83 & 45 & 14 & 21,9 & Tidak Lulus & 65,9 \\
\hline 42 & 45 & 14 & 27,3 & Lulus & 86,3 & 84 & 40 & 14 & 21,9 & Lulus & 77,5 \\
\hline 43 & 0 & 0 & 14,4 & Tidak Lulus & 14,4 & 85 & 42,5 & 14 & 18,3 & Lulus & 76,5 \\
\hline 44 & 40 & 14 & 21 & Tidak Lulus & 61,6 & 86 & 45 & 14 & 20,1 & Lulus & 77,4 \\
\hline 45 & 42,5 & 14 & 0 & Tidak Lulus & 59 & 87 & 45 & 14 & 26,4 & Lulus & 85,4 \\
\hline 46 & 42,5 & 14 & 24,6 & Lulus & 83,6 & 88 & 45 & 14 & 22,8 & Lulus & 81,8 \\
\hline 47 & 42,5 & 14 & 16,5 & Lulus & 74,6 & 89 & 0 & 14 & 14,4 & Tidak Lulus & \\
\hline 48 & 42,5 & 14 & 16,5 & Lulus & 74,6 & 90 & 40 & 14 & 20,1 & Lulus & 76,6 \\
\hline 49 & 42,5 & 14 & 7,2 & Tidak Lulus & 49,5 & 91 & 0 & 0 & 14,4 & Tidak Lulus & 14,4 \\
\hline 50 & 45 & 14 & 21 & Lulus & 79,2 & 92 & 22,5 & 14 & 18,3 & Tidak Lulus & 47,3 \\
\hline 51 & 0 & 0 & 14,4 & Tidak Lulus & 14,4 & 93 & 22,5 & 14 & 22,8 & Tidak Lulus & 65,1 \\
\hline 52 & 40 & 14 & 14,4 & Lulus & 70,1 & 94 & 45 & 14 & 18,3 & Lulus & 77,3 \\
\hline 53 & 35 & 0 & 15,6 & Tidak Lulus & 53,9 & 95 & 45 & 0 & 24,6 & Tidak Lulus & 69,6 \\
\hline 54 & 42,5 & 14 & 13,5 & Lulus & 70,8 & 96 & 45 & 14 & 24,6 & Lulus & 81,9 \\
\hline 55 & 42,5 & 14 & 20,1 & Lulus & 77,4 & 97 & 22,5 & 14 & 17,4 & Tidak Lulus & 46,4 \\
\hline 56 & 30 & 14 & 17,4 & Tidak Lulus & 65,6 & 98 & 45 & 14 & 24,6 & Lulus & 82 \\
\hline 57 & 45 & 14 & 24,6 & Lulus & 83,6 & 99 & 42,5 & 14 & 23,7 & Lulus & 81 \\
\hline 58 & 37,5 & 0 & 12,6 & Tidak Lulus & 52,6 & 100 & 42,5 & 14 & 22,8 & Lulus & 79,3 \\
\hline 59 & 40 & 14 & 18,3 & Lulus & 73,1 & 101 & & 0 & 20,1 & Tidak Lulus & 20,1 \\
\hline 60 & 42,5 & 14 & 21,9 & Lulus & 79,2 & 102 & & 14 & 19,2 & Tidak Lulus & 19,2 \\
\hline 61 & 42,5 & 0 & 18,3 & Tidak Lulus & 61,6 & 103 & 322,5 & 14 & 16,5 & Tidak Lulus & 59,6 \\
\hline 62 & 46,25 & 14 & 24,6 & Lulus & 84,4 & 104 & 45 & 14 & 23,7 & Tidak Lulus & 67,7 \\
\hline 63 & 40 & 14 & 20,1 & Lulus & 75,7 & 105 & 42,5 & 14 & 20,1 & Lulus & 76,6 \\
\hline 64 & 37,5 & 14 & 12,6 & Tidak Lulus & 51,7 & 106 & 42,5 & 14 & 24,6 & Lulus & 81,1 \\
\hline 65 & 22,5 & 0 & 21,9 & Tidak Lulus & 36,9 & 107 & 78,75 & 14 & 0 & Tidak Lulus & 26,5 \\
\hline 66 & 41,25 & 0 & 11,7 & Tidak Lulus & 53,4 & 108 & 43,75 & 14 & 18,3 & Lulus & 77,3 \\
\hline 67 & 45 & 14 & 21,9 & Lulus & 80,9 & 109 & 42,5 & 14 & 25,5 & Lulus & 82,8 \\
\hline 68 & 41,25 & 0 & 22,8 & Tidak Lulus & 65,3 & 110 & 42,5 & 14 & 25,5 & Lulus & 82,8 \\
\hline 69 & 45 & 14 & 22,8 & Lulus & 81 & 111 & 45 & 14 & 23,7 & Lulus & 83,5 \\
\hline 70 & 22,5 & 14 & 22,8 & Tidak Lulus & 51,8 & 112 & 0 & 14 & 17,4 & Tidak Lulus & 17,4 \\
\hline 71 & 42,5 & 14 & 20,1 & Lulus & 77,4 & 113 & 22,5 & 14 & 13,5 & Tidak Lulus & 57,5 \\
\hline 72 & 45 & 14 & 24,6 & Lulus & 83,6 & 114 & 22,5 & 14 & 20,1 & Tidak Lulus & 49,1 \\
\hline 73 & 40 & 14 & 25,5 & Lulus & 82 & 115 & 36,25 & 0 & 20,1 & Tidak Lulus & 44,3 \\
\hline 74 & 42,5 & 14 & 21,9 & Lulus & 79,2 & 116 & 42,5 & 14 & 19,2 & Lulus & 76,5 \\
\hline 75 & 42,5 & 14 & 13,5 & Tidak Lulus & 69,2 & 117 & 45 & 14 & 19,2 & Lulus & 78,2 \\
\hline 76 & 42,5 & 14 & 12,6 & Tidak Lulus & 54,9 & 118 & 45 & 14 & 19,2 & Lulus & 78,2 \\
\hline 77 & 40 & 14 & 21 & Lulus & 76,6 & 119 & 45 & 14 & 20,1 & Lulus & 79,1 \\
\hline 78 & 17,5 & 14 & 15,6 & Tidak Lulus & 57,1 & 120 & 42,5 & 14 & 20,1 & Lulus & 75,7 \\
\hline 79 & 42,5 & 14 & 21,9 & Lulus & 78,4 & 121 & 45 & 14 & 25,5 & Lulus & 84,5 \\
\hline 80 & 45 & 14 & 28,2 & Lulus & 87,2 & & & & & & \\
\hline
\end{tabular}


Raden Roro Martiningsih: Dampak Bimtek Daring Pembatik Level Dua Terhadap Kemampuan Tik Guru Provinsi Jawa Timur

Berdasarkan Tabel 3 di atas diperoleh data peserta yang aktif membuat RPP, membuat video, aktif mengikuti diskusi, dan mengikuti ujian akhir, serta yang dinyatakan lulus level 2 , masing-masing ditunjukkan sebagaimana Tabel 4 s.d. Tabel 9 berikut ini.

1. Dari 121 guru yang aktif, 104 orang (85,95\%) membuat RPP dan yang tidak membuat RPP 17 orang $(14,05 \%)$ sebagaimana Tabel 4 di bawah ini.

Tabel 4. Pembuatan RPP

\begin{tabular}{lcc}
\hline Tugas Membuat RPP & Jumlah & Persentase \\
\hline Tidak Membuat RPP & 17 & 14,05 \\
\hline Membuat RPP & 104 & 85,95 \\
\hline Jumlah & 121 & 100 \\
\hline
\end{tabular}

2. Dari 121 guru yang aktif, 109 orang $(90,08 \%)$ membuat video dan yang tidak membuat video 12 orang $(9,92 \%)$ sebagaimana Tabel 5 di bawah ini.

Tabel 5. Pembuatan Video

\begin{tabular}{lcc}
\hline Tugas Membuat Video & Jumlah & Persentase \\
\hline Tidak mengumpulkan & 12 & 9,92 \\
\hline Membuat Video & 109 & 90,08 \\
\hline Jumlah & $\mathbf{1 2 1}$ & $\mathbf{1 0 0}$ \\
\hline
\end{tabular}

3. Dari 121 guru yang aktif, 105 orang $(86,78 \%)$ melakukan diskusi pada fitur Forum DIskusi dan yang tidak berdiskusi 16 orang (13,22\%) sebagaimana Tabel 6 di bawah ini.

Tabel 6. Diskusi

\begin{tabular}{lcc}
\hline Tugas Diskusi & Jumlah & Persentase \\
\hline Tidak Diskusi & 16 & 13,22 \\
\hline Melakukan Diskusi & 105 & 86,78 \\
\hline Jumlah & $\mathbf{1 2 1}$ & $\mathbf{1 0 0}$ \\
\hline
\end{tabular}

4. Dari 121 guru yang aktif, 117 orang (96,69\%) mengikuti ujian akhir dan yang tidak melakukan ujian akhir 4 orang $(3,31 \%)$ sebagaimana Tabel 7 berikut.
Tabel 7. Ujian Akhir

\begin{tabular}{lrc}
\hline Ujian Akhir & Jumlah & Persentase \\
\hline Tidak Mengikuti & 4 & 3,31 \\
\hline Mengikuti Ujian & 117 & 96,69 \\
\hline Jumlah & $\mathbf{1 2 1}$ & $\mathbf{1 0 0}$ \\
\hline
\end{tabular}

5. Dari 121 guru yang aktif, 76 orang $(62,81 \%)$ dinyatakan lulus dan yang tidak lulus 45 orang $(37,19 \%)$ sebagaimana Tabel 8 di bawah ini.

Tabel 8. Kelulusan

\begin{tabular}{lcc}
\hline Kelulusan & Jumlah & Persentase \\
\hline Tidak Lulus & 45 & 37,19 \\
\hline Lulus & 76 & 62,81 \\
\hline Jumlah & 121 & 100 \\
\hline
\end{tabular}

Manfaat Bimtek PembaTIK level 2 secara daring bagi peserta adalah memudahkan guru untuk mengikuti pelatihan/bimtek tanpa harus hadir secara fisik ke lokasi pelatihan/bimtek. Mereka bisa mengikuti pelatihan/bimtek dari mana saja, kapan saja, dan tentunya dengan biaya yang lebih murah. Mereka bisa mengikuti proses pembelajaran di tempat kerjanya dengan menggunakan fasilitas yang tersedia di kantornya. Dari sisi anggaran pelatihan/ bimtek relatif lebih efisien terutama penghematan komponen perjalanan dinas, akomodasi dan konsumsi, penggandaan materi, dan lain sebagainya.

Penyelenggaraan pelatihan/bimtek yang mengintegrasikan TIK memiliki kelebihan dan kekurangan. Ini bisa menjadi wacana dan pilot project bagi perluasan kesempatan peningkatan SDM guru di Indonesia.

Bimtek PembaTIK Level Dua ini adalah pelatihan online, yang dilakukan dalam jaringan internet (Mardawani, 2020: 162). Pelatihan online dapat dijadikan langkah terobosan yang bisa mengakomodasi perkembangan dan mengoptimalkan pendayagunaan TIK dalam pelaksanaan pelatihan. Era globalisasi yang mengedepankan penggunaan internet dalam segala bidang pekerjaan ini mendorong semua bidang untuk bisa mengolaborasikan kegiatannya. Internet bisa menjadi tool yang 
Raden Roro Martiningsih: Dampak Bimtek Daring Pembatik Level Dua Terhadap Kemampuan Tik Guru

Provinsi Jawa Timur

sangat bermanfaat jika didayagunakan (Susilawati, 2016: 351).

Bimtek daring pemanfaatan Rumah Belajar ini menggunakan sistem pembelajaran elektronik atau e-pembelajaran yang merupakan cara yang dianggap sesuai dalam proses belajar-mengajar. E-learning merupakan konsekuensi logis dari perkembangan teknologi informasi dan komunikasi. Menggunakan e-learning, peserta ajar (learner) dapat berperan aktif dalam pencarian informasi maupun pengetahuan baru, serta pengiriman materi pembelajaran melalui media elektronik seperti internet (Permatasari, 2018: 2).

Salah satu pemanfaatan internet sebagai model pembelajaran daring yang disediakan oleh pemerintah Indonesia adalah melalui portal Rumah Belajar. Rumah Belajar merupakan jenis portal pendidikan berbasis teknologi yang diluncurkan sejak 15 Juli 2011 oleh Mendikbud Indonesia. Saat ini Portal Rumah Belajar dapat diunduh melalui google playstore maupun web https://belajar. kemdikbud.go.id/secara gratis. Portal Rumah Belajar adalah portal belajar yang menyediakan sistem tata kelola pembelajaran yang dapat digunakan guru dan peserta didik dalam mengelola kegiatan pembelajaran di kelas secara virtual (Yanti, 2020: 62).

Bagi daerah atau wilayah yang telah tersedia infrastrutur internet, bukan berarti mudah dalam menerapkan pembelajaran jarak jauh melalui daring. Konsep pembelajaran daring merupakan konsep yang tidak mudah dan banyak kendala yang akan dihadapi, bahkan guru perlu mendapatkan pelatihan tentang bagaimana cara melaksanakan pembelajaran secara daring. Untuk itu perlu adanya pelatihan kepada guru-guru agar terlaksananya kegiatan secara daring dengan baik sesuai tujuan yang diinginkan (Setiawan, 2020: 38).

Bimtek PembaTIK Level Dua merupakan upaya untuk mengembangkan sumber daya manusia, terutama untuk peningkatan profesionalitas agar terjadi peningkatan kemampuan yang menyangkut kemampuan kerja, berpikir, dan keterampilan (Hidayat, 2017: 72).

Hambatan yang dialami peserta selama Bimtek PembaTIK Level Dua berlangsung adalah bahwa peserta dengan kemampuan TIK yang pas-pasan otomatis akan mengundurkan diri karena merasa tidak mampu melanjutkan kegiatan level dua yang menyebabkan mereka tidak aktif. Rasa tidak percaya diri dan khawatir bersaing dengan guru lain yang lebih hebat, kurangnya sarana dan prasarana yang pendukung aktivitas di level dua juga merupakan pemicu peserta menjadi tidak aktif. Solusi pemecahan masalah yang dilakukan oleh Duta Rumah Belajar 2017 agar peserta yang tidak aktif menjadi aktif adalah melakukan pembimbingan melalui email atau media komunikasi Whatsapp, menelpon, dan bila memungkinkan mengunjungi peserta di sekolah tempat peserta bertugas.

Secara keseluruhan, peserta Bimtek daring puas dengan pelatihan yang fleksibel. Dengan pelatihan daring, peserta pelatihan tidak terkendala waktu dan tempat di mana mereka dapat mengikuti pelatihan, baik dari rumah masing-masing maupun dari tempat kerja. Dengan bimtek daring, fasilitator memberikan materi melalui aplikasi Simpatik yang dapat diakses tanpa terikat ruang dan waktu. Kondisi ini membuat peserta Bimtek Daring PembaTIK Level 2 dapat secara bebas memilih tugas mana yang harus dikerjakan lebih dahulu. Fleksibilitas waktu, metode pembelajaran, dan tempat dalam pembelajaran daring berpengaruh terhadap kepuasan peserta pelatihan terhadap Bimtek Daring PembaTIK Level 2 (Sadikin, 2020: 219).

Bimtek PembaTIK Daring ini menerapkan proses komunikasi dan informasi dari tutor kepada peserta yang berisi informasi-informasi Bimtek dengan melibatkan unsur pendidik dengan memanfaatkan berbagai media sebagai sarana penyajian ide, gagasan, dan materi bimtek kepada peserta. Beberapa bagian unsur ini mendapatkan sentuhan media teknologi informasi, sehingga mencetuskan lahirnya ide tentang online learning.

Bimtek Daring PembaTIK Level 2 merupakan sistem pelatihan yang dilakukan dengan menggunakan perangkat atau alat bantu menggunakan akses internet dan teknologi informasi yang baik untuk menjadi fasilitas dalam kegiatan Bimtek Daring PembaTIK Level 2 melalui interaksi yang 
Raden Roro Martiningsih: Dampak Bimtek Daring Pembatik Level Dua Terhadap Kemampuan Tik Guru Provinsi Jawa Timur

dilakukan (Salsabila, 2020: 4). Bimtek Daring PembaTIK Level 2 memberikan perubahan dari yang sebelumnya kombinasi konvensional dengan teknologi menjadi seluruhnya dengan teknologi. Tentu saja akan mendapat ragam tanggapan (Damanik, 2020: 124).

Pemanfaatan teknologi telekomunikasi untuk kegiatan pelatihan di Indonesia semakin kondusif dengan munculnya sistem pelatihan daring (Mustofa, 2019: 155). Keberhasilan Bimtek Daring PembaTIK Level 2 sangat tergantung dari beberapa komponen baik peserta pelatihan, fasilitator, materi pelatihan, maupun teknologi informasi. Komponenkomponen tersebut harus terintegrasi sehingga benar-benar dapat menghasilkan peserta pelatihan yang berkualitas untuk Bimtek Daring PembaTIK Level 3.

\section{SIMPULAN DAN SARAN}

\section{Simpulan}

Esensi temuan hasil penelitian ini adalah Bimtek PembaTIK Level Dua merupakan upaya untuk mengembangkan sumber daya manusia, terutama untuk peningkatan profesionalitas agar terjadi peningkatan kemampuan yang menyangkut kemampuan kerja, berpikir, dan keterampilan.

Dampak Bimtek Daring bagi peserta adalah memudahkan guru untuk mengikuti pelatihan. Mereka dapat mengikuti pelatihan dari mana saja, kapan saja, dan tentunya dengan biaya yang lebih murah. Hambatan yang dialami peserta adalah rasa tidak percaya diri, di mana mereka khawatir bersaing dengan guru lain yang lebih hebat. Selain itu, kurangnya sarana dan prasarana yang mendukung aktivitas peserta Bimtek Daring PembaTIK Level 2 juga merupakan pemicu peserta menjadi tidak aktif. Hambatan tersebut diatasi dengan komunikasi yang baik antara peserta dan fasilitator

Transformasi digital yang terjadi mengubah kebiasaan masyarakat. Ada yang secara cepat dapat beradaptasi, ada pula yang lamban dalam beradaptasi. Harapannya adalah bahwa agar seluruh elemen cepat beradaptasi sehingga tidak mengalami kendala dalam keberlanjutan usaha yang dilakukan.
Bimtek Daring PembaTIK Level 2 merupakan salah satu langkah pemanfaatan teknologi jaringan dan teknologi informasi bagi pengembangan sistem pelatihan dalam jaringan yang dikelola pada aplikasi learning management system (LMS) melalui url simpatik.belajar.kemdikbud.go.id dan diharapkan dapat menjadi sarana yang efektif bagi para peserta pelatihan dalam mempelajari ilmu tanpa batas. Proses pelatihan dengan cara ini dinilai sangat baik, karena materi pelatihan dapat digunakan dengan gratis oleh seluruh peserta yang membutuhkan. Peserta pelatihan yang ada di daerah terpencil dapat mengakses materi Bimtek Daring PembaTIK Level 2. Proses pelatihan ini menarik bagi peserta karena penyampaian data yang disiapkan dalam aplikasi Simpatik mudah untuk dicerna sehingga membuat peserta pelatihan menjadi tertantang ingin lebih tahu dan mendalami materi yang mereka perlukan.

\section{Saran}

Perbaikan materi pelatihan untuk Bimtek PembaTIK Level Dua di tahun mendatang perlu disesuaikan dengan perkembangan ilmu pengetahuan yang terus berkembang sehingga mampu mengembangkan sumber daya manusia, terutama untuk peningkatan profesionalitas agar terjadi peningkatan kemampuan yang menyangkut kemampuan kerja, berpikir, dan keterampilan. Di sisi lain, Bimtek PembaTIK Daring pada tahun mendatang penting dilanjutkan karena fleksibiltasnya yang memudahkan peserta mengikuti pelatihan. Mereka dapat mengikuti pelatihan dari mana saja, kapan saja, dan tentunya dengan biaya yang lebih murah. Namun, perbaikan aplikasi Simpatik di tahun berikutnya merupakan hal penting dan priortitas dilakukan oleh penyelenggara karena transformasi digital yang terjadi selalu berkembang sehingga tidak mengalami kendala dalam keberlanjutan layanan yang dilakukan.

Untuk menjaring peserta yang lebih luas, perlu sosialisasi terus menerus tentang Bimtek Daring PembaTIK Level 2 yang diharapkan dapat menjadi sarana yang efektif 
Raden Roro Martiningsih: Dampak Bimtek Daring Pembatik Level Dua Terhadap Kemampuan Tik Guru Provinsi Jawa Timur

bagi para peserta pelatihan dalam mempelajari ilmu tanpa batas.

Baik Kualitas maupun kuantitas penyelenggaraan pelatihan online hendaknya terus ditingkatkan. Peningkatan secara kuantitas meliputi peningkatan jumlah guru yang menjadi peserta pelatihan TIK maupun semakin meningkatnya jumlah kabupaten/ kota per provinsi secara nasional yang menugaskan guru mengikuti pelatihan.

Pentingnya peran fasilitator dalam memotivasi peserta yang dituangkan dalam perencanaan kegiatan pelatihan online di tahun berikutnya sehingga peningkatan kompetensi TIK guru di wilayah Indonesia semakin merata.

Peserta yang lulus Bimtek Daring PembaTIK Level 2 diharapkan dapat berbagi pengetahuan dan keterampilan TIK kepada guru lainnya dan pelajar di wilayahnya. Dengan demikian, guru dan pelajar yang memiliki kompetensi TIK juga meningkat.

\section{PUSTAKA ACUAN}

Adiyanta, F.C. Susila. (2019). Hukum dan Studi Penelitian Empiris: Penggunaan Metode Survey sebagai Instrumen Penelitian Hukum Empiris. Universitas Diponegoro.Adminitrative Law \& Governance Journal. Volume 2 Issue 4, Nov 2019 ISSN. 2621 - 2781 Online Administrative Law \& Governance Journal. Volume 2 Issue 4, November 2019.

Astuti, Ratih Artwiantini. (2016). Pengembangan Modul IPA Terpadu Berbasis Empat Pilar Pendidikan dengan Tema Pantai untuk Meningkatkan Sikap IImiah Siswa Kelas VII SMP/MTs. Universitas Sebelas Maret. Jurnal Inkuiri. Vol 5, No. 2, 2016ISSN: 2252-7893, (hal 40-51).

Damanik, Renata DN. (2020). Tata Kelola Pelaksanaan E-Learning Dalam Peningkatan Kinerja Penyelenggaraan Pelatihan Dalam Masa Covid-19. Pusat Pelatihan Manajemen dan Kepemimpinan Pertanian Kementerian Pertanian RI. Jurnal Agri Widya (Menginspirasi Untuk Pelatihan Yang Lebih Baik). VOLUME 1 NO. 3 - SEPTEMBER 2020.

Elyas, Ananda Hadi. (2018). Penggunaan Model Pembelajaran E-Learning Dalam
Meningkatkan Kualitas Pembelajaran. Universitas Dharmawangsa. Jurnal Warta. Edisi: 56 April 2018 | ISSN: 1829-7463 Universitas Dharmawangsa.

Fitriyadi, Herry. (2013). Integrasi Teknologi Informasi Komunikasi dalam Pendidikan: Potensi Manfaat, Masyarakat Berbasis Pengetahuan, Pendidikan Nilai, Strategi Implementasi dan Pengembangan Profesional. Universitas Negeri Yogyakarta. Jurnal Pendidikan Teknologi dan Kejuruan. Volume 21, Nomor 3, Mei 2013.

Hariani, Pipit Putri, dkk. (2020). Pemanfaatan ELearning Pada Pembelajaran Jarak Jauh di Masa Pandemi Covid-19. Universitas Muhammadiyah Sumatera Utara. Biblio Couns: Jurnal Kajian Konseling dan Pendidikan. | Vol. 3 No. 2 Juli 2020.

Hidayat. (2017). Pengaruh Diklat (Pendidikan Dan Pelatihan) Terhadap Prestasi Kerja Karyawan Di Bank BPR Rokan Hulu. Universitas Pasir Pengaraian. Jurnal IImiah Cano Ekonomos. Vol. 6 No. 1 Januari 2017.

Julifan, Joko Ahmad. (2015). Efektifitas Manajemen Pendidikan dan Pelatihan Berbasis Kompetensi Bagi Guru. Universitas Pendidikan Indonesia. Jurnal Administrasi Pendidikan. Vol.XXII No. 2 Oktober 2015.

Kornelius. (2014). Pendidikan dan Pelatihan Guru dalam Meningkatkan Kualitas Pendidikan di SMP Negeri 27 Sendawan Kabupaten Kutai Barat. Universitas Mulawarman. eJournal Administrative Reform. 2014, 2 (3): 1811-1823 ISSN 2338-7637, ar.mian.fisip-unmul.ac.id ( Copyright 2014.

Kurnianingsih, Indah. (2017). Upaya Peningkatan Kemampuan Literasi Digital bagi Tenaga Perpustakaan Sekolah dan Guru di Wilayah Jakarta Pusat Melalui Pelatihan Literasi Informasi. Universitas Negeri Medan. Jurnal Pengabdian Kepada Masyarakat. JPKM. Vol. 3, No. 1, September 2017, Hal 61-76 DOI: http://doi.org/10.22146/jpkm.25370.ISSN 2460-9447 (print), ISSN 2541-5883 (online).

Kurniati, Dian. (2014). Pengembangan Model Pembelajaran Analisis Real Berbasis Web Dalam Bentuk E-Learning. Universitas Jember. Jurnal Kadikma. Vol. 5, No. 3, hal 112, Desember 2014. 
Raden Roro Martiningsih: Dampak Bimtek Daring Pembatik Level Dua Terhadap Kemampuan Tik Guru Provinsi Jawa Timur

Landistyas, Lutfandita. (2012). Rancang Bangun Pengelolaan Data Peserta Diklat Berbasis Web (Studi Kasus: Balai Teknologi Komunikasi Pendidikan DIY). Universitas Amikom Yogyakarta. Jurnal Dasi. Vol. 13 No. 1 Maret 2012 ISSN: 1411-3201.

Linarwati, Mega. (2016). Studi Deskriptif Pelatihan dan Pengembangan Sumber Daya Manusia Serta Penggunaan Metode Behavioral Event Interview dalam Merekrut Karyawan Baru di Bank Mega Cabang Kudus. Universitas Pandanaran Kudus. Journal of Management. Vol. 2 No. 2, Maret 2016.

Mardawani, dkk. (2020). Pelatihan Pembelajaran Daring Google Classroom Bagi Guru Di SMP Negeri 6 Sintang 2020. STKIP Persada Khatulistiwa, Sintang. Jurnal PEKAN. Vol.5 No. 2 Edisi November 2020.

Marti. (2018). Pelajar Abad 21 Harus Kuasai Empat Pilar Hidup. Pimpinan Wilayah Muhammadiyah Surabaya. Majalah Online. PWMU.https://pwmu.co/70728/07/30/pelajarabad-21-harus-kuasai-empat-pilar-hidupseperti-ini/.

Mulyadi, Rindy. (2015). Pengaruh Pemanfaatan E-Learning Menggunakan "Portal Rumah Belajar Kemendikbud" Terhadap Hasil Belajar Siswa Pada Mata Pelajaran Ilmu Pengetahuan Alam. (Skripsi). Universitas Pendidikan Indonesia Bandung. repository.upi.edu.

Mustofa, Mokhamad Iklil. (2019). Formulasi Model Perkuliahan Daring Sebagai Upaya Menekan Disparitas Kualitas Perguruan Tinggi (Studi terhadap Website pditt.belajar.kemdikbud. go.id). Walisongo Journal of Information Technology, Vol. 1 No. 2 (2019): 151-160 DOI : http://dx.doi.org/10.21580/wjit.2019.1.2.4067 Copyright (C) 2019 WJIT: Walisongo Journal of Information Technology WJIT: Walisongo Journal of Information Technology - Vol.1 No. 2 (2019) 151.

Mutmainah, Siti. (2017). Studi Kelayakan Pengembangan Aplikasi Bank Soal dalam Rumah Belajar. Jurnal Teknodik. Pustekkom Kemendikbud.

Nova, Sari Puti. (2018). Efektivitas Komunikasi Aplikasi telegram Sebagai Media Informasi Pegawai PT Pos Indonesia (Persero) Kota
Pekanbaru. Universitas Riau. Jurnal Online Mahasiswa. JOM JOM FISIP. Vol. 5 No. 1 April 2018 FISIP Vol. 5 No. 1 April 2018.

Permatasari, Indah. (2018). Pengaruh E-Learning Sebagai Media Pelatihan dan Pengembangan Terhadap Kinerja Karyawan BCA KCU Tangerang. LPPM STMIK Atma Luhur. Jurnal SISFOKOM. Volume 07, Nomor 01, Maret 2018.

Richardo, Rino. (2016). Program Guru Pembelajar: Upaya Peningkatan profesionalisme Guru di Abad 21. Universitas Sebelas Maret. Prosiding Seminar Matematika dan Pendidikan Matematika. ISBN: 978-6026122-20-9 hal 777-785 November 2016 http:/ /jurnal.fkip.uns.ac.id.

Sadikin, Ali. (2020). Pembelajaran Daring di Tengah Wabah Covid-19 (Online Learning in the Middle of the Covid-19 Pandemic) Ali Sadikin. BIODIK Jurnal IImiah Pendidikan Biologi ISSN 2580-0922 (online), ISSN 24602612 (print) Volume 6, Nomor 02, Tahun 2020, Hal. 214-224.

Salsabila, Unik Hanifah. (2020). Pemanfaatan Teknologi Media Pembelajaran di Masa Pandemi Covid-19. Trapsila: Jurnal Pendidikan Dasar | p-ISSN 2685-7642 | eISSN 2685-8207 Vol.2 No.2 Desember 2020 Hal 1-13 1.

Setiawan, Tabah Heri. (2020). Pelatihan Daring Teknologi Pembelajaran. Universitas Pamulang, Tangerang Selatan. Jurnal Pengabdian Kepada Masyarakat - Aphelion. Vol. 01 No. 01, Agustus 2020.

Susilawati, Eni. (2016). Analisis SWOT Penyelenggaraan Diklat Online Teknologi Informasi dan Komuikasi (TIK) Bagi Guru. Kemdikbud. Jurnal Pendidikan dan Kebudayaan. Vol. 1, Nomor 3, Desember 2016.

Yanti, Minanti Tirta. (2020). Pemanfaatan Portal Rumah Belajar Kemendikbud Sebagai Model Pembelajaran Daring Di Sekolah Dasar. Institut Hindu Dharma Negeri Denpasar. Adi Widya: Jurnal Pendidikan Dasar Fakultas Dharma Acarya. 